Article

\title{
Development of an Urban High-Resolution Air Temperature Forecast System for Local Weather Information Services Based on Statistical Downscaling
}

\author{
Chaeyeon $\mathrm{Yi}^{1}{ }^{1}$, Yire Shin ${ }^{1}$ and Joon-Woo Roh $^{2, *}$ \\ 1 Research Center for Atmospheric Environment, Hankuk University of Foreign Studies, Yongin-si, \\ Gyeonggi-do 17035, Korea; prpr.chaeyeon@gmail.com (C.Y.); shinyire@hanmail.net (Y.S.) \\ 2 Atmospheric Program, School of Earth and Environmental Sciences, Seoul National University, \\ Seoul 08826, Korea \\ * Correspondence: neolegacy@gmail.com; Tel.: +82-10-6521-2035
}

Received: 30 November 2017; Accepted: 12 February 2018; Published: 26 April 2018

check for updates

\begin{abstract}
The Korean peninsula has complex and diverse weather phenomena, and the Korea Meteorological Administration has been working on various numerical models to produce better forecasting data. The Unified Model Local Data Assimilation and Prediction System is a limited-area working model with a horizontal resolution of $1.5 \mathrm{~km}$ for estimating local-scale weather forecasts on the Korean peninsula. However, in order to numerically predict the detailed temperature characteristics of the urban space, in which surface characteristics change rapidly in a small spatial area, a city temperature prediction model with higher resolution spatial decomposition capabilities is required. As an alternative to this, a building-scale temperature model was developed, and a $25 \mathrm{~m}$ air temperature resolution was determined for the Seoul area. The spatial information was processed using statistical methods, such as linear regression models and machine learning. By comparing the accuracy of the estimated air temperatures with observational data during the summer, the machine learning was improved. In addition, horizontal and vertical characteristics of the urban space were better represented, and the air temperature was better resolved spatially. Air temperature information can be used to manage the response to heat-waves and tropical nights in administrative districts of urban areas.
\end{abstract}

Keywords: heat-wave; statistical downscaling; weather information service; building-scale air temperature; heat-exposure map

\section{Introduction}

With increasing global urbanization and intensifying climate change, climate and weather disasters, as well as socio-economic problems in urban areas, are rising [1,2]. Disastrous events, such as heat and cold waves, heavy rainfall, and air pollution, are becoming more serious because of climate change, threatening public health and socio-economic safety. In particular, because rapid urbanization is increasing the variability of temperature in cities, the ability of cities to respond to heat stress is becoming weaker in urban areas. Furthermore, temperature-related mortality rates have been increasing in recent years as a result of both the aging population in many developed countries and increased extreme weather phenomena [3,4]. In order to prioritize and protect those vulnerable to extreme temperature variability, providing accurate and useful weather warning information at appropriate times is crucial [5]. 
The World Meteorological Organization (WMO) has been making efforts to improve this by organizing and conducting various conferences related to urban meteorology and climate. For example, to promote research on high-impact weather in cities, the first World Weather Open Science Conference [6] was held for a gathering of scientists and users who use weather data to share information. In particular, the importance of an information and communication system for urban-scale weather/climate risks has been emphasized [7]. At the 2015 International Conference on Urban Climate [8], the application of urban climate information and its services were discussed. The development of high-resolution numerical weather prediction techniques through various means, such as quantitatively and qualitatively increased observational data, improved numerical modeling, and data assimilation, has been described to produce weather and climate information in more detail. Various methods for providing detailed spatial and temporal weather information pertaining to the urban sector were discussed in depth [9-13]. According to research trends that indicate that the production of meteorological information should be transmitted in a form that is easy for users to understand, the UK Meteorological (Met) Office developed impact forecasts [5]. For example, in the public health sector, a warning system, which constitutes a response plan at each of the five alert levels, has been developed to provide weather information for ensuring public health safety.

In the fifth edition of the Intergovernmental Panel on Climate Change (IPCC) 'Summary for policymakers [14]', it is stated that many risks from climate change are concentrated in urban areas. It also emphasizes that urban resilience to climate change and sustainable development can accelerate successful climate change adaptation.

Urban heat stress poses a serious risk to urban residents, and the risk related to heat stress is stronger in areas with weak urban infrastructure and areas where appropriate measures are lacking [15]. In addition to climate change, the risk of heat stress is amplified by the increased intensity of the heat island phenomenon due to urbanization, decreased vegetation in urban areas, increased building density, and increased energy consumption [16]. To address these issues, strengthening basic information is necessary for the diagnosis of, prediction of, and response to urban heat stress. In addition, the construction of resilient infrastructure systems for extreme weather events such as heat stress can significantly reduce thermal vulnerability and exposure in urban areas.

Since the 1960s, urbanization has been accelerating in South Korea. In particular, Seoul metropolitan areas have become overcrowded. Due to decreased latent heat fluxes and increased daytime heat storage induced by urbanization, air temperatures in urban areas have increased compared to surrounding non-urban areas [17]. The increased sensible heat flux and artificial heat, which include air conditioning systems and vehicles, have also increased the urban nighttime temperature $[18,19]$. As a representative event of high temperature in Korea, the regular weather observation network established in 1973 recorded a heat-wave period in 1994. During this period, a total of over 3300 deaths occurred due to high temperatures [20]. The number of days with heat-waves (more than two days with maximum temperatures above $33^{\circ} \mathrm{C}$ is the warning criterion from the Korea Meteorological Administration) and tropical nights (a daily minimum temperature above $25^{\circ} \mathrm{C}$ ) in Seoul were 29 and 36, respectively. These figures are extremely high compared to the averages of 6.6 days and 8.4 days for heat-waves and tropical nights in Seoul, respectively. The second highest heat-wave in Seoul occurred in 2016; the heat-waves and tropical nights lasted for 24 days and 32 days, respectively [21]. In the Seoul metropolitan area, the number of tropical nights is higher than that of daytime heat-waves.

Considering patients and deaths attributable to summer-time heat-waves, the critical temperature of the excess mortality rate is determined by the relationship between mortality rate and air temperature [22-24]. For example, the critical temperature range in Korea was calculated to be $27-30^{\circ} \mathrm{C}$, depending on the region, in Seoul and other cities [25]. The relationship among daily maximum temperatures, critical temperatures, and excess death incidents reflects regional differences [26]. Thus, urban areas in the Korean Peninsula, especially the megacity of the Seoul metropolitan area, which has a population of over 25 million, are exposed more frequently to the risk of heat-waves during the 
summer. Therefore, accurate and detailed information on the regional thermal environmental impact is required to ensure public health safety in large urban areas.

Korea's high-temperature health warning system (HHWS) is operated during the summer for 14 major cities in South Korea [27]. The HHWS provides high-temperature warning information as one value for each major city, as well as information on population density, building structure, and topography, taking into account the size and complexity of each city. In the case of Seoul, more detailed high-temperature warning information based on daily maximum temperatures is provided for five regions classified through cluster analysis [28]. The high-temperature warning information for each of the five regions is used to estimate the mortality rate during a heat-wave period. To further obtain more detailed thermal environmental information for Seoul, a weather forecasting system with building-scale and street-level resolution is required to reflect the complex and diverse local surface physics processes in areas around Seoul [29].

Micro-climate studies have been conducted to analyze and verify high-temperature warning information in urban areas with building-scale spatial resolution [30]. Kim et al. [31] developed an empirical statistical model that explains the relationship between daily maximum temperature and excess mortality rate by calculating hourly temperature from mean radiation temperature, which is affected by terrain and structure, and not from the current near-surface air temperature. They found that, in general, mortality related to heat was significantly reduced by changes in the structural characteristics of the urban space (changes in the spatial characteristics of buildings and vegetation) in a redeveloped new city. Because urban structures and vegetation are variable, a spatial distribution calculation model based on micro-climate prediction with varying urban structures is required to determine the temperature variability around buildings [32]. With a high resolution that can resolve building-scale forecasting information, the operations and management department of a city must plan to implement such a system to reduce the heat stress on public health [33,34].

The purpose of this study is to estimate spatially resolved air temperatures at the building-scale and street-level through calibration with weather forecasting data, using precise urban surface parameters.

\section{Data and Method}

\subsection{Target Domain}

The target study area is Seoul, the capital of the Republic of Korea and one of the Asian megacities. The geographical characteristics of Seoul are briefly described as follows. Seoul has an area of approximately $605 \mathrm{~km}^{2}$. It has a basin-like topography with five mountains that are more than $500 \mathrm{~m}$ above sea level in the north and several relatively small mountains in its eastern and southern parts. The mean elevation above sea level is $54.7 \mathrm{~m}$, which is much lower than the elevations of the metropolitan area at $131.7 \mathrm{~m}$ and the Korean Peninsula at $427 \mathrm{~m}$ [35]. The Han River zonally runs through the center of Seoul, and seven tributaries of the Han River are distributed throughout the Seoul metropolitan area (Figure 1).

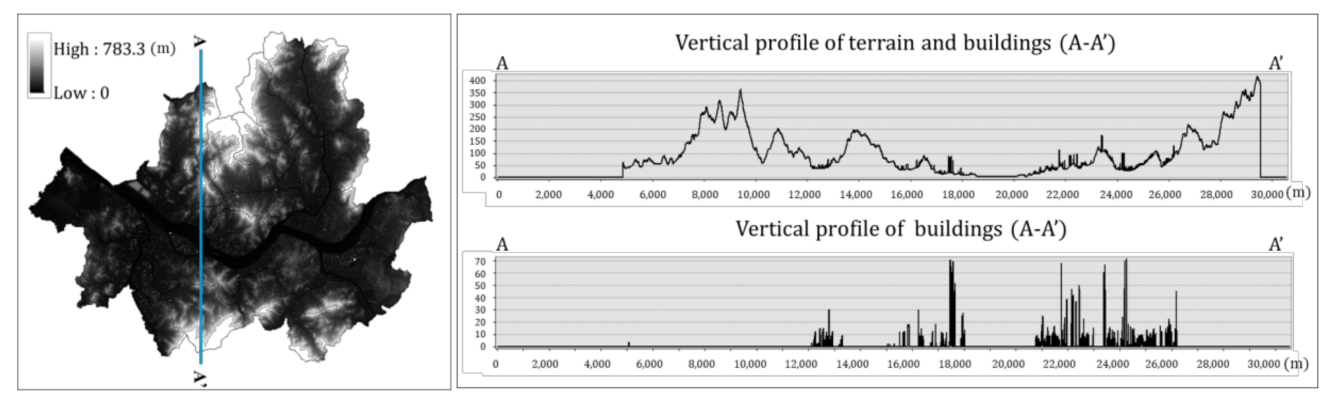

Figure 1. Topography map and vertical profile of Seoul. Data source: National Geographic Information Institute (NGII, Korea). 
The Seoul metropolitan area is a densely populated area with a population of over 10 million people. The characteristics of the terrain are complex, with high-density buildings, mountains, rivers, and basin-shaped environments. These characteristics aggravate environmental problems, including adverse weather conditions. For example, urban development induces population inflows, changes in land use and structure, increases in energy use, and so on. Under these conditions, the increase in traffic interferes with the dispersion of air pollutants. These factors all contribute to the formation of urban heat islands. Residential, commercial, industrial, and green areas cover 53.8\%, 4.18\%, 3.29\%, and $38.7 \%$, respectively, of the land area of Seoul. The urbanization area ratio in 2015 was $61.3 \%$ (Figure 2, Table 1). Furthermore, according to the types of buildings and land, Seoul predominantly falls under types 2 and 4 of the Local Climate Zone classification system [36]. In this study, a maximum air temperature model was developed for the Seoul area. The forecasts conducted with this model are presented and evaluated in Section 4. For a detailed evaluation of the results, the Songpa area was selected. This area consists of various city structures (e.g., various building shapes, a wide distribution of vegetation, and notable waterfront areas).

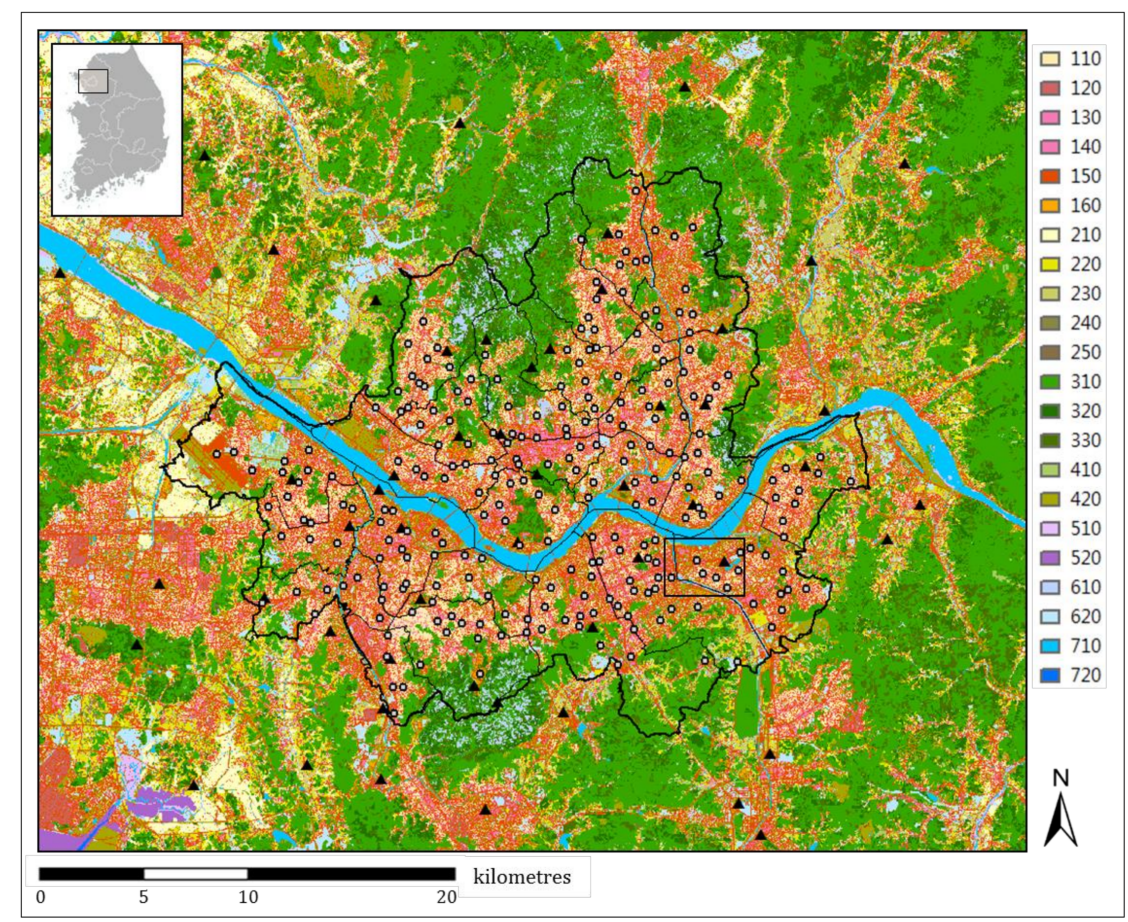

Figure 2. Seoul area (black thick curve), land use (color shading), and KMA/SKT AWSs (Korea Meteorological Administration; black solid triangle/open circle). Legend (right) shows land color codes indicating identical ground surface cover in an area. The black square is the Songpa area, which is our detailed spatial analysis area. A description of the legend is given in Table 1. Data source: Ministry of Environment (MOE, Korea).

Table 1. Classification of ground surface covering and their respective percentages.

\begin{tabular}{cccc}
\hline Class & Description & Ha & $\mathbf{\%}$ \\
\hline 110 & Residential area & 8171 & 13.46 \\
120 & Industrial area & 120 & 0.20 \\
130 & Commercial area & 4542 & 7.48 \\
140 & Cultural and recreational area & 570 & 0.94 \\
150 & Traffic area & 16,342 & 26.92 \\
160 & Public utility area & 1491 & 2.46 \\
\hline
\end{tabular}


Table 1. Cont.

\begin{tabular}{cccc}
\hline Class & Description & Ha & $\mathbf{\%}$ \\
\hline 210 & Rice paddy & 279 & 0.46 \\
220 & Upland field & 806 & 1.33 \\
230 & Facility plantation & 243 & 0.40 \\
240 & Orchard & 43 & 0.07 \\
250 & Other plantations & 108 & 0.18 \\
310 & Broadleaf forest & 9817 & 16.17 \\
320 & Coniferous forest & 2605 & 4.29 \\
330 & Mixed stand forest & 1883 & 3.10 \\
410 & Natural grassland & 1158 & 1.91 \\
420 & Artificial grassland & 5731 & 9.44 \\
510 & Inland wetland/shore vegetation & 215 & 0.35 \\
610 & Natural bare soil & 870 & 1.43 \\
620 & Artificial bare soil & 2405 & 3.96 \\
710 & Inland water & 3300 & 5.44 \\
\hline
\end{tabular}

\subsection{Unified Model (UM) Local Data Assimilation and Prediction System (LDAPS) Forecasting Data}

The numerical forecasting system currently in operation at the Korea Meteorological Administration (KMA) is a system constructed by introducing the Unified Model (UM), which was developed by the UK Met Office in May 2008. The KMA has been running the Global Data Assimilation and Prediction System (GDAPS) since May 2009 and the Regional Data Assimilation and Prediction System (RDAPS) as a forecasting model since May 2010. The KMA is also operating a local forecasting model, the Local Data Assimilation and Prediction System (LDAPS), based on a unified model to predict the risk of damages and to overcome the spatial resolution and time-scale limitations of global and regional forecasting models [37].

The spatial resolution of the UM LDAPS is $1.5 \mathrm{~km}$, and it comprises 70 layers-up to approximately $40 \mathrm{~km}$ in the vertical direction (producing detailed forecast information with a higher spatial resolution than UM RDAPS). It receives its boundary fields from the global model 8 times per day (00:00, 06:00, 12:00, 18:00 UTC and 03:00, 09:00, 15:00, 21:00 UTC), every $3 \mathrm{~h}$. Furthermore, it 10operates as a self-analysis and prediction circulation system using a three-dimensional variational data assimilation technique. In particular, the ground physics process uses the JULES (the Joint UK Land Environment Simulator) land surface scheme (LDAPS operation manual). In this study, the air temperature forecasting data of LDAPS, which is used as an independent variable in the development of the Building-scale Resolved air Temperature (BRT) model, are the lowest single layer (surface layer, not one of the vertical layers) data, and the $2 \mathrm{~m}$ height air temperature data are among the diagnostic variables calculated from the prognostic equations.

In this study, UM LDAPS data from June to August 2015 were used to predict temperatures at the time of data extraction (09:00 to 21:00 KST). For this purpose, the latest 12-h forecast data were extracted from the 36-h forecast data for every 00:00 UTC (09:00 KST). The spatial distribution of the daytime maximum temperatures from UM LDAPS was interpolated to $25 \mathrm{~m}$ resolution using the IDW (Inverse Distance Weighting) technique.

\subsection{Ground Observation Data}

As a dependent variable, Automated Weather Station (AWS) data operated by KMA were used as training data for the BRT model and verification information for the air temperature prediction results. Surface meteorological data are observed at the weather stations, which include the Seoul weather station (SWS, station number 108), 51 KMA AWS stations, and 255 SKT AWS stations in the Seoul area. The KMA AWSs observed various meteorological variables, such as temperature, humidity, wind speed, pressure, and precipitation for every $1 \mathrm{~min}$ at $1.5 \mathrm{~m}$ height (from the rooftop of buildings or at ground level). Hourly temperature data from the 52 AWSs (SWS and 51 AWSs) 
were collected to determine daily maximum air temperature from June to August 2015. The AWS weather data were used as the main data for determining the BRT distribution, because they reflect the weather phenomenon between the atmosphere and the surface layer. In addition, another source of meteorological data was considered to verify the estimated temperature data in the BRT model. SKT AWSs are operated by a telecommunication company (SK Techx Co., Ltd., Seoul, Korea), and their observation equipment is installed on the roofs of buildings at 255 sites in Seoul (see Figure 2). In this study, cases for clear days were used for verification. Prior to using available data, a temperature data quality test was performed according to the quality control manual for national climate data [38]. The test involves a physical range check, frequency distribution check, step check, flat line (persistence) check, and median filter check [39]. Based on the test results, 91\% of total SKT AWS data could be used as available temperature data (from June to August 2015).

\subsection{Urban Surface Parameters Using the Climate Analysis Seoul (CAS) Workbench}

The CAS (Climate Analysis Seoul) workbench is a simulator for analyzing urban surface characteristics (land cover, density of buildings, and vegetation) and the spatial distribution of the micro-climate (thermal and wind environment) from urban surface parameters [29]. In this study, the CAS workbench was used to reflect the local surface characteristics for the BRT model. Sixteen surface characteristic parameters, such as elevation, slope angle, aspect ratio, and fractional coverage ratio (i.e., water surface, vegetated surface, tall vegetation, unvegetated surface, built-up surface) of $25 \mathrm{~m}$ resolution were used as independent variable input data. The near-surface temperature of urban areas depends on their size and land use type. Therefore, the factors listed in Table 2 were calculated to apply the unique locality of urban areas. The spatial distributions of the sixteen surface parameters were determined, and each parameter was extracted at 52 points at the same position as the KMA observation sites. Each parameter was averaged from grids within a radius of $100 \mathrm{~m}$ from the site and input to the BRT model.

Table 2. Urban surface characteristic parameters. Data source: National Geographic Information Institute (NGII, Korea).

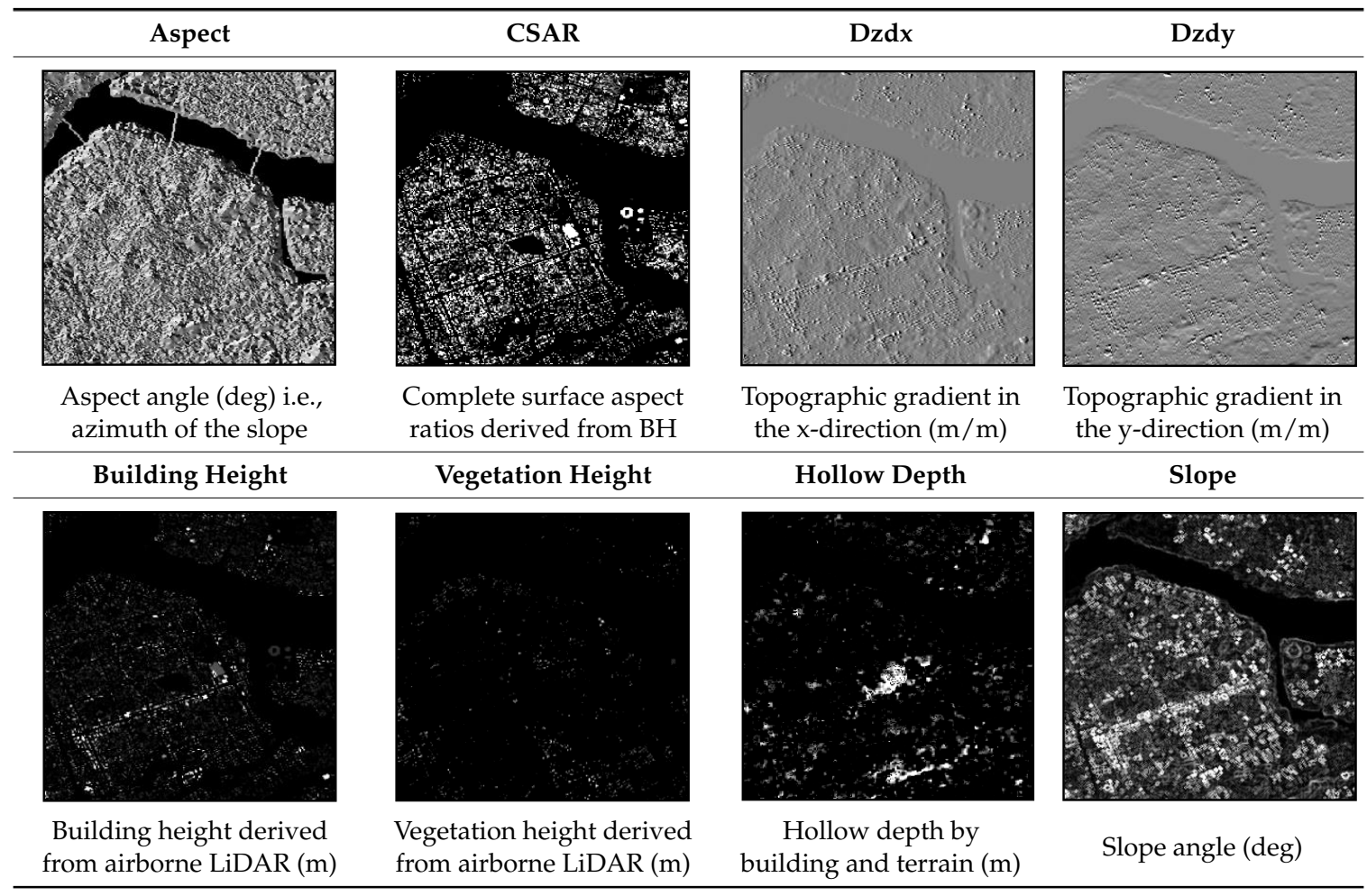


Table 2. Cont.

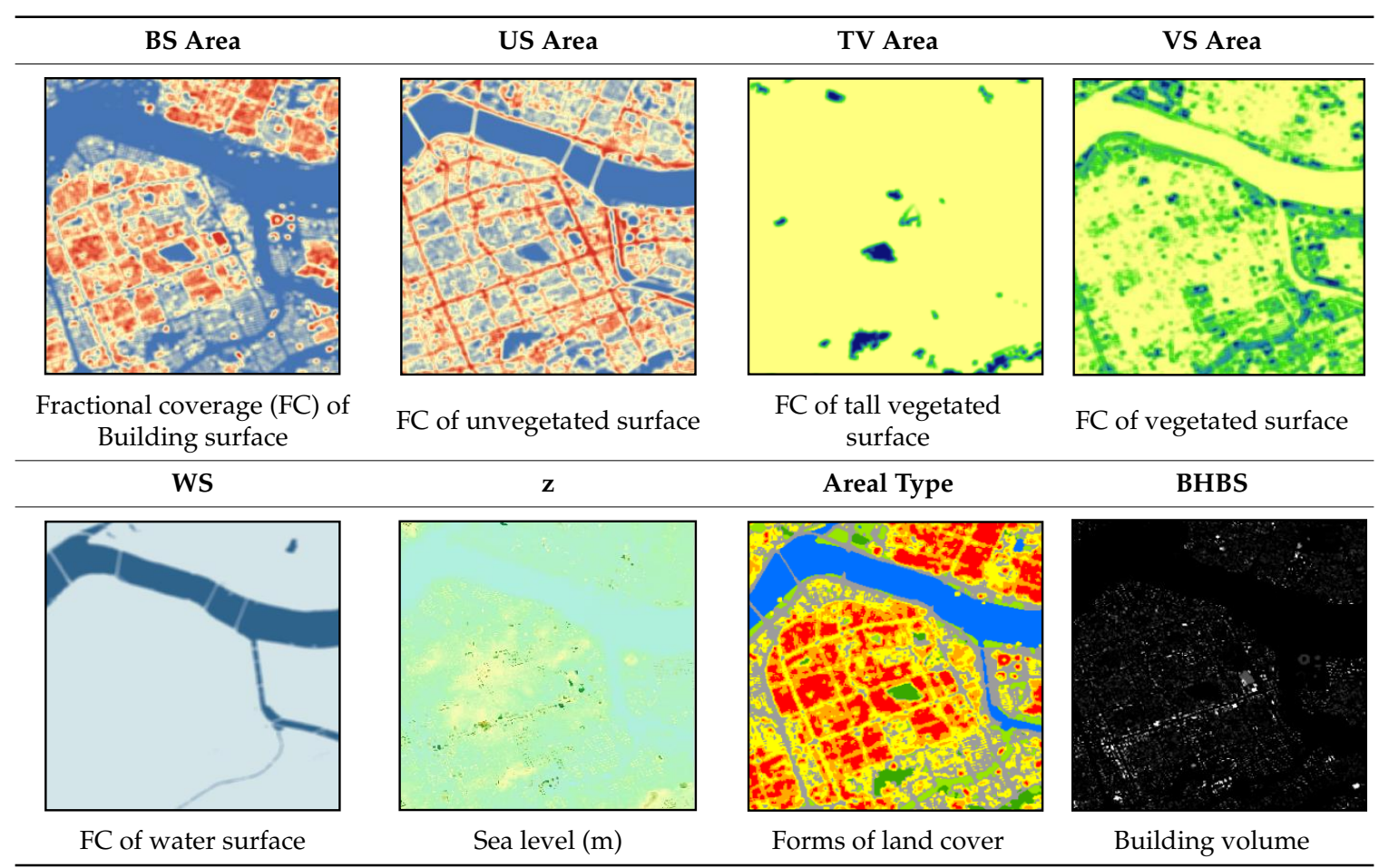

\subsection{Building-Scale Resolved Air Temperature (BRT) Model Development and Process}

Statistical models are widely used in urban weather and climate studies [40-43]. In order to produce BRT with very high resolution, ground observation temperature data from 52 KMA AWSs with irregular points, UM LDAPS temperature data from a numerical weather forecasting model, and the 16 types of urban surface parameters through the CAS workbench were used as training data, based on statistical methods (see Table 3 and Figure 3). In this process, two statistical methods-a linear regression model and machine learning-were used for the production of BRT. The linear regression model (LM) is a stochastic model and a statistical technique used to predict the likelihood of an event using a linear combination of fixed input variables [44]. A support vector machine (SVM), which is a machine learning algorithm, is mainly used for classification of the given training data $[45,46]$. In order to include updated recent weather conditions in the training data, a 'sliding window' approach was applied as the meteorological data processing algorithm in the development of the BRT model. In this approach, air temperature for the next day is predicted using the last 30 days of data as training data during the study period. In order to determine the heat exposure index, precipitation days were left out of the training dataset for high temperature prediction, because extreme high temperature days do not occur alongside precipitation.

Table 3. The purpose and description of the dataset used in the development and evaluation of the Building-scale Resolved air Temperature (BRT) model.

\begin{tabular}{cll}
\hline Data & \multicolumn{1}{c}{ Description } & \multicolumn{1}{c}{ Purpose } \\
\hline & & 52 data points corresponding to predicted variables \\
& of KMA AWSs for spatial matching: independent \\
UM LDAPS & voriables (JJA 2015) as training data for the BRT \\
& numerical model & model (excluding precipitation days) \\
& Grid data: BRT production for spatial distribution \\
\hline
\end{tabular}


Table 3. Cont.

\begin{tabular}{cll}
\hline \multicolumn{1}{c}{ Data } & \multicolumn{1}{c}{ Description } & \multicolumn{1}{c}{ Purpose } \\
\hline KMA AWS & Observation data at 52 sites & $\begin{array}{l}\text { 52 data points: dependent variables (JJA 2015) as } \\
\text { training data for the BRT model } \\
\text { (excluding precipitation days) } \\
\text { Verification of estimated temperature (JAS 2015) }\end{array}$ \\
\hline SKT AWS & Observation data at 255 sites & $\begin{array}{l}\text { Verification of estimated temperature (JAS 2015) } \\
\text { (excluding precipitation days) } \\
\text { 255 data points }\end{array}$ \\
\hline $\begin{array}{c}\text { Urban surface } \\
\text { parameters }\end{array}$ & $\begin{array}{l}\text { Surface characteristics data } \\
\text { (16 types) from the CAS workench }\end{array}$ & $\begin{array}{l}\text { 52 data for the BRT model } \\
\text { Grid data: BRT production for spatial distribution }\end{array}$ \\
\hline
\end{tabular}

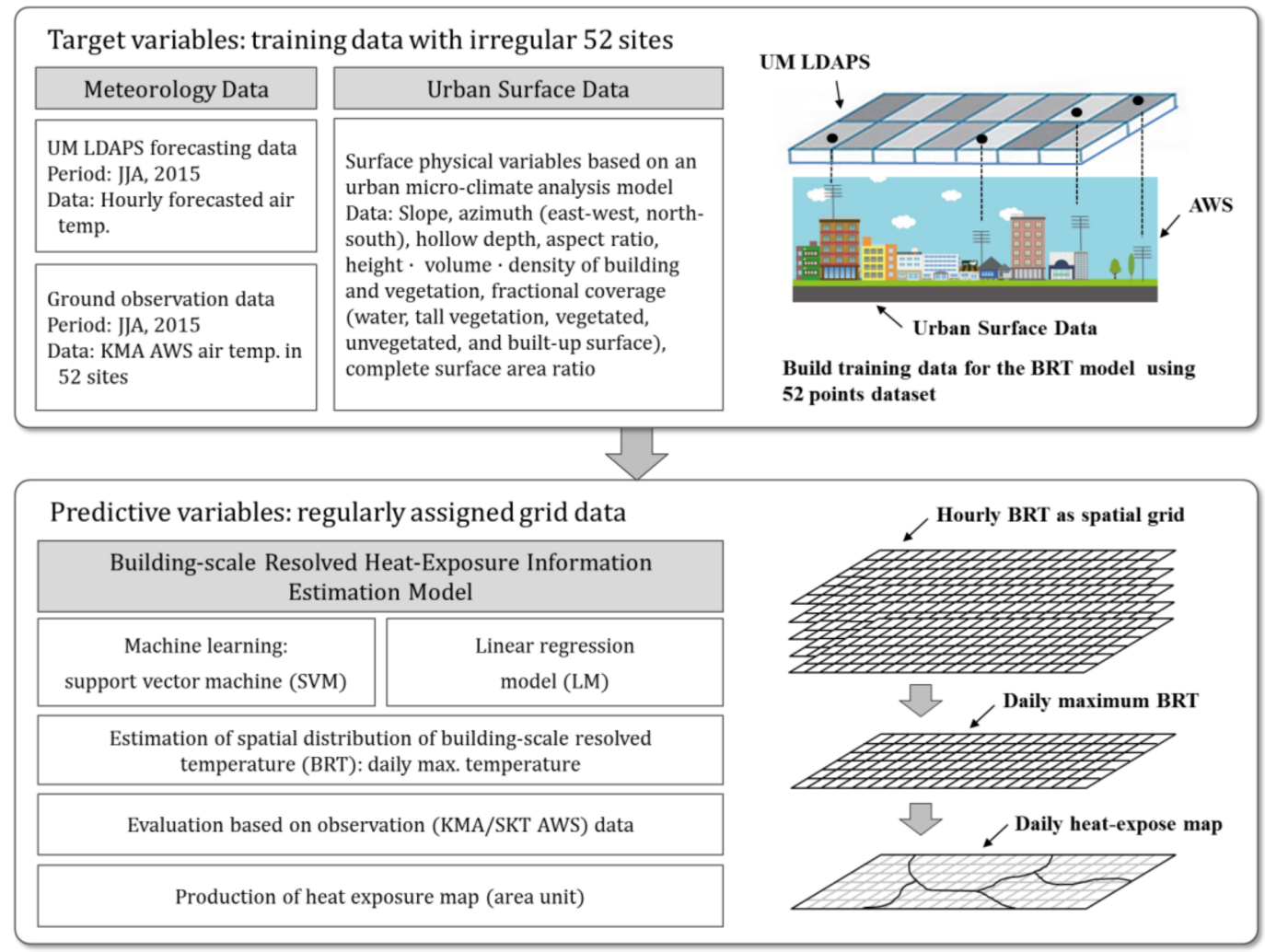

Figure 3. Flow chart of the development of the BRT model.

\section{Preliminary Study Results: Characteristics of Meteorological Data in Seoul}

The Seoul weather station (SWS) records its temperature on behalf of Seoul area. However, various temperature distributions are observed in the Seoul area since its urban structure is inhomogeneous. Daily maximum temperatures were analyzed for the hottest July-August period, which is a typical summer period for Korea. During this period, urban areas exhibit temperature differences. The daily maximum temperature of $24-36{ }^{\circ} \mathrm{C}$ was observed at SWS. The observed daily maximum temperature in the IQR (Interquartile Range) for 52 AWSs was $28-37{ }^{\circ} \mathrm{C}$, and the daily mean of the maximum temperature was $24-31{ }^{\circ} \mathrm{C}$ (Figure 4 ). The daily maximum temperature exhibited wide differences among the 52 AWSs. It is presumed that local urban surface characteristics affect the spatial distribution of the local air temperature [47]. 


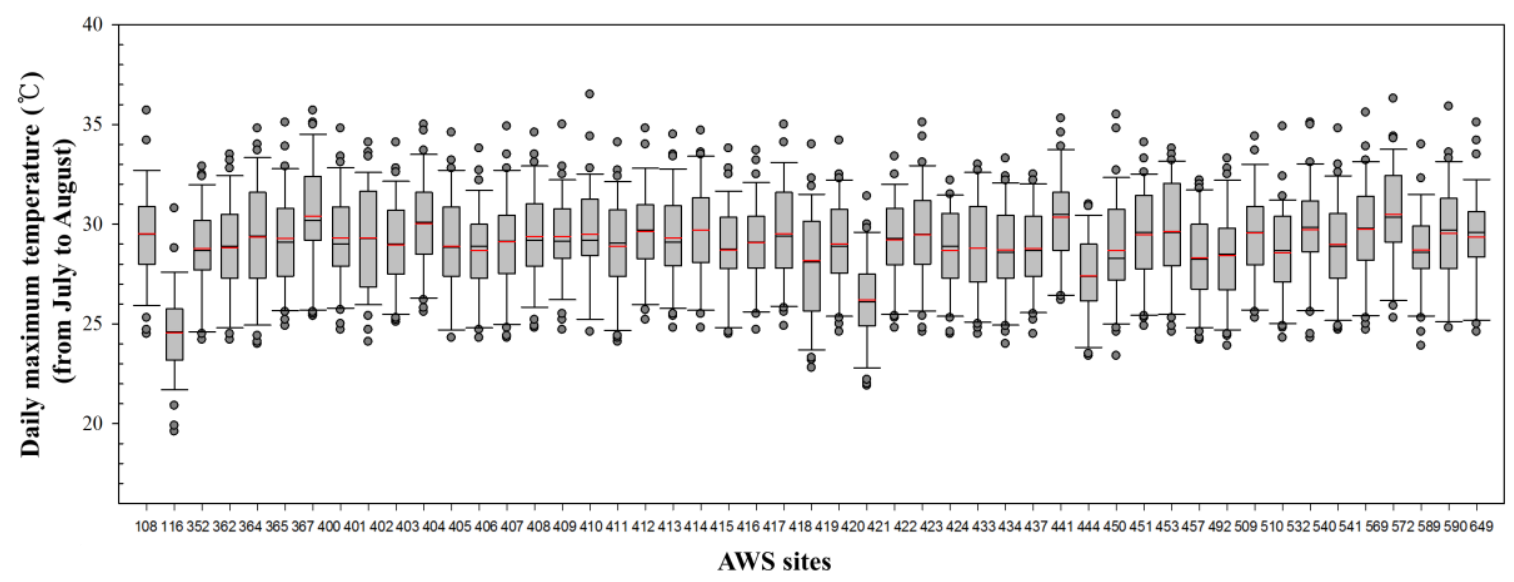

Figure 4. Distribution of the daily maximum air temperature variability of 52 Automated Weather Station (AWSs) during July to August 2015.

Figure 5 shows a comparison among the mean differences of daily maximum and minimum air temperatures (hereafter $\mathrm{DT}_{\mathrm{MAX}}$ and $\mathrm{DT}_{\mathrm{MIN}}$ ), which are among the most important weather variables for the summer season from July to August 2015 in the 52 AWSs (including SWS). In order to determine the relative differences in air temperature around Seoul, the air temperatures of the other 51 AWSs were used.

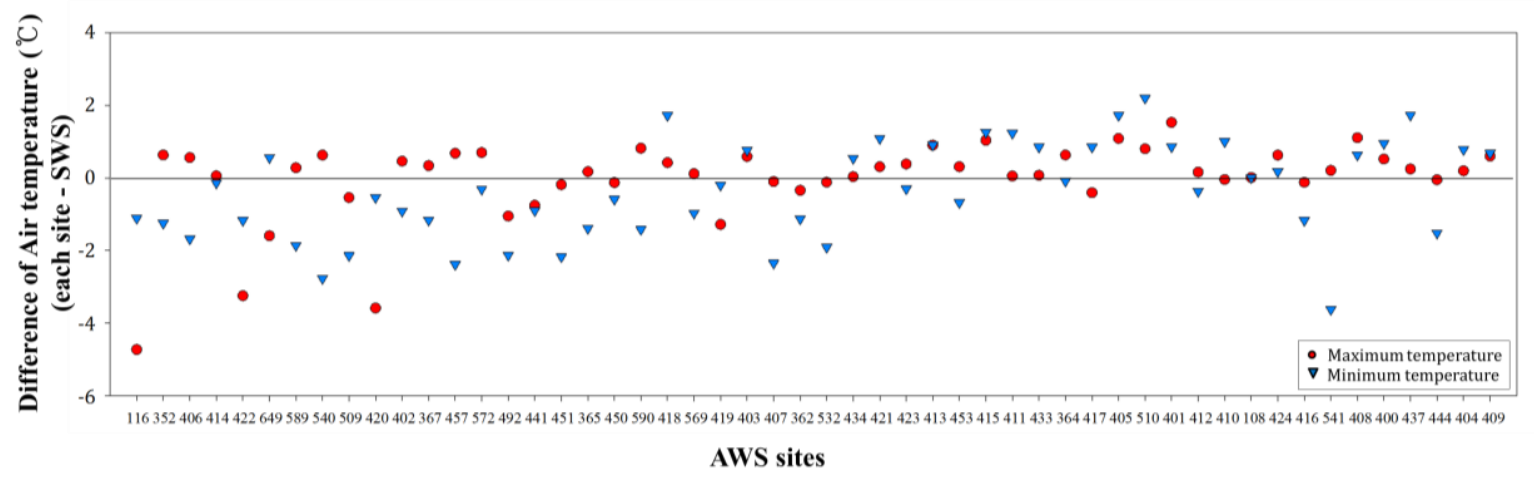

Figure 5. Mean difference of daily maximum air temperature (red circles) and daily minimum air temperature (blue triangles) for air temperatures observed in Seoul weather station (SWS) during July to August 2015.

The x-axis represents sequentially sorted AWSs according to impervious area ratios, which were calculated using the land coverage area ratio within a radius of $100 \mathrm{~m}$ from each of the 52 AWSs. The impervious area ratio increases towards the right side. For example, the leftmost AWS, number 116 , has a $0 \%$ impervious area ratio, and the rightmost AWS, number 409 , has a $99.4 \%$ impervious area ratio. The $y$-axis shows $\mathrm{DT}_{\mathrm{MAX}}$ and $\mathrm{DT}_{\mathrm{MIN}}$, which are the differences in $\mathrm{T}_{\mathrm{MAX}}$ and $\mathrm{T}_{\mathrm{MIN}}$ between each station and SWS. Overall, $\mathrm{DT}_{\mathrm{MAX}}$ and $\mathrm{DT}_{\mathrm{MIN}}$ tended to increase to the right side with larger impervious area ratios, and the difference between $\mathrm{DT}_{\mathrm{MAX}}$ and $\mathrm{DT}_{\mathrm{MIN}}$ tended to decrease. The trend of $\mathrm{DT}_{\mathrm{MIN}}$ was stronger than that of $\mathrm{DT}_{\mathrm{MAX}}$, showing that nighttime $\mathrm{DT}_{\mathrm{MIN}}$ increased with higher impervious area ratios. In other words, within Seoul's urban area, spatial differences in air temperature increase for stations that are located in areas with large variations in topography and land use. 


\section{Results and Discussion}

The estimated BRTs were evaluated using observational data. A selected case study for the spatial distribution on a typical hot day is shown in Section 4.1. The evaluation of time series during the period and the spatial distribution for clear days using KMA ground observation data are discussed in Sections 4.2.1 and 4.2.2, respectively. The verification of BRT using 255 SKT AWS data, which are higher resolution and not applied to the development of the BRT, is shown in Section 4.2.3.

\subsection{Estimation of $B R T$}

In order to investigate more detailed high temperatures in an urban area, a representative example of a high-temperature case on 30 August 2015 was selected. On this day, the weather was hot during the daytime and mostly clear and calm. Figure 6 shows the time series of temperature, pressure, wind, and humidity from 00:00 to 24:00 KST (Korea Standard Time: UTC + 09 h) at KMA station SWS. The daily mean, maximum, and minimum temperatures were recorded to be $24.9{ }^{\circ} \mathrm{C}, 31.0^{\circ} \mathrm{C}$, and $19.9{ }^{\circ} \mathrm{C}$, respectively. The diurnal variation of temperature was also distinct on this sunny day. Relative humidity also appeared to be inversely proportional to daily temperature variability. Wind speed was $0-2 \mathrm{~m} / \mathrm{s}$ in the morning and increased to approximately $5 \mathrm{~m} / \mathrm{s}$ in the afternoon. Northerly winds occurred in the morning but shifted to southerly winds from 10:00 to 12:00 KST and then to westerly winds in the afternoon. These weather phenomena were governed by the synoptic-scale weather pattern (Figure 7). In order to describe the atmospheric structure on this day, $1^{\circ}$ by $1^{\circ}$ NCEP FNL (National Centers for Environmental Prediction Final Operational Global Analysis data) reanalysis data from NCAR (National Center for Atmospheric Research) were used. In the 700-hPa weather chart (Figure 7a), a mid-latitude cyclone accompanying high relative humidity can be observed towards the north end of the Korean Peninsula. A quasi-stationary front and subtropical high were located south and southeast of the Korean Peninsula. The weather on 30 August 2015 was relatively dry and sunny, because the Korean Peninsula was located between the two systems. The area around Seoul can be described as having a dry condition in the $850-\mathrm{hPa}$ equivalent potential temperature (Figure $7 \mathrm{~b}$ ).

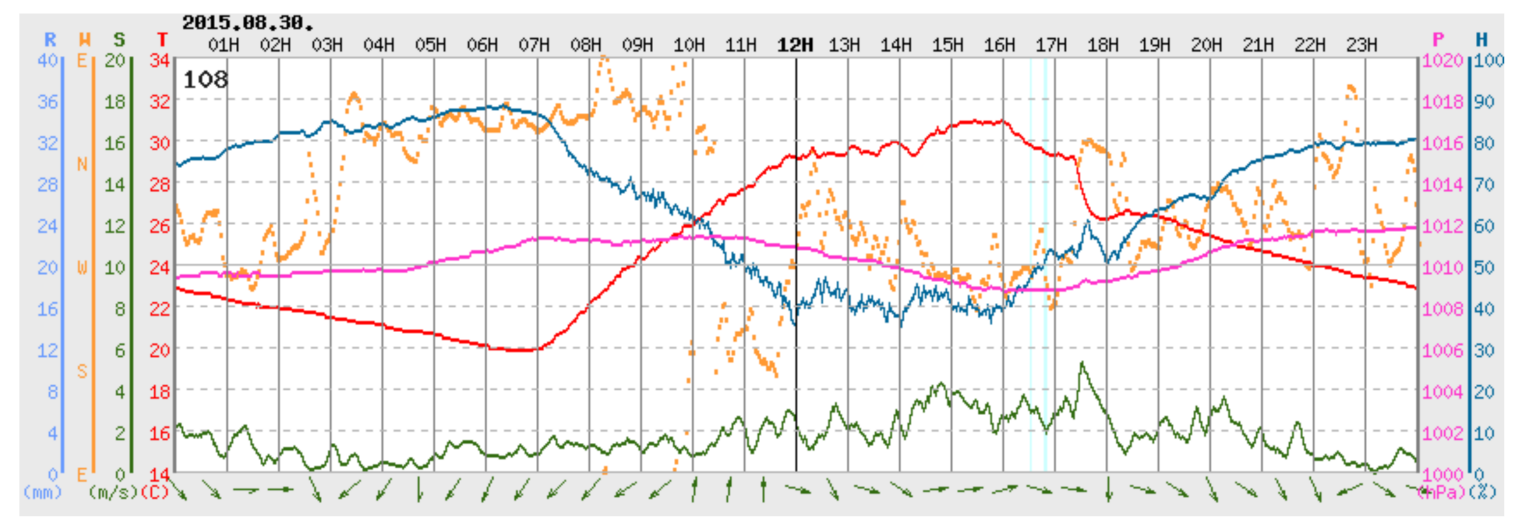

Figure 6. Time series of meteorological variables from Korea Meteorological Administration (KMA) Automated Weather Station (AWS) number 108 (Seoul weather station, SWS) for the entire day [local time] of 30 August 2015: Temperature (red line, $\left[{ }^{\circ} \mathrm{C}\right]$ ), pressure (pink line, [hPa]), wind direction (orange dots, degrees), wind speed (green lines and green wind vectors at the bottom of the figure), and relative humidity (blue line, [\%]) at the surface. Data source: www.kma.go.kr (Korea Meteorological Administration). 
(a) $700 \mathrm{hPa}$ GPH, T, ReHUM, \& WIND 20150830_0000z

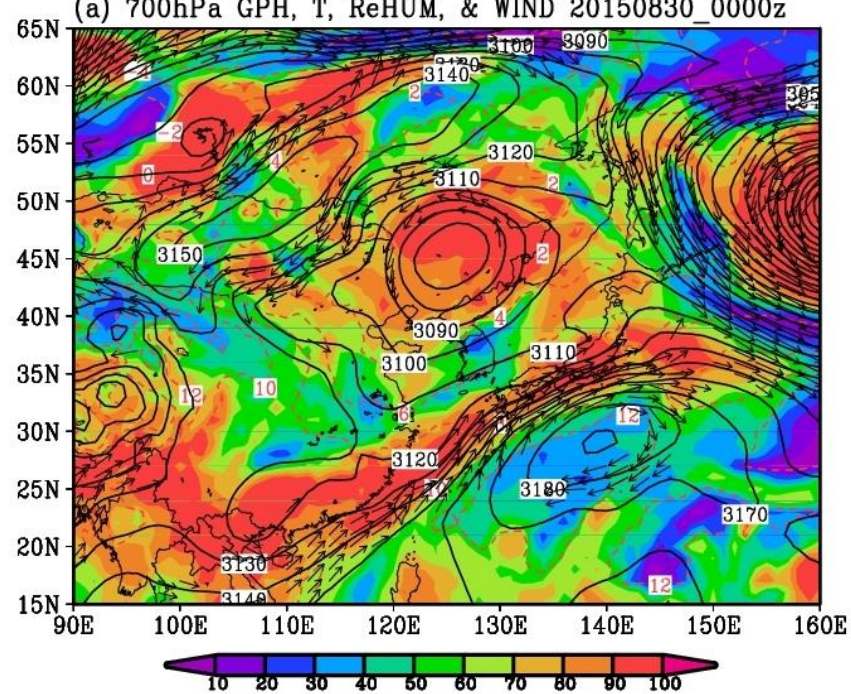

(b) 850EPT \& WIND 20150830_0000z

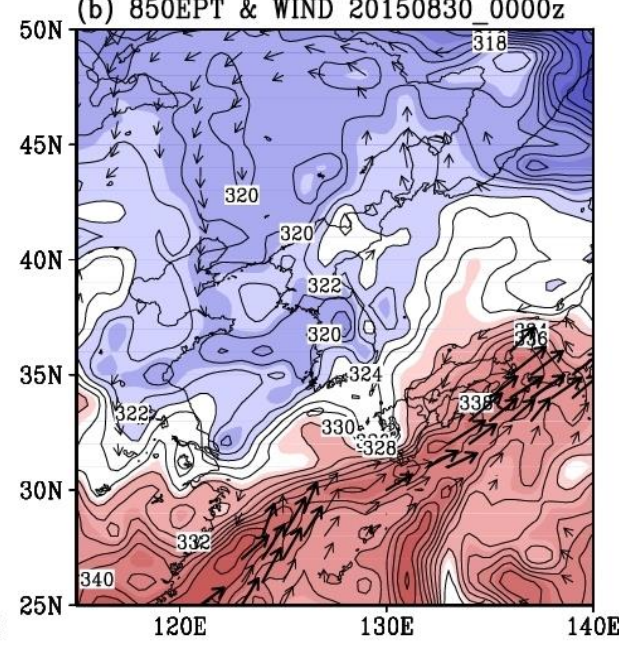

Figure 7. Weather charts at 00:00 UTC 30 August 2015: (a) 700-hPa geopotential height (contoured at 10 gpm intervals with solid lines), temperature (contoured at $2{ }^{\circ} \mathrm{C}$ intervals with red dashed lines), relative humidity (shaded rainbow colors), and wind $>8 \mathrm{~m} / \mathrm{s}$ (vector); and (b) 850-hPa equivalent potential temperature (blue shaded below $324 \mathrm{~K}$ and red shaded over $330 \mathrm{~K}$ ), wind $>5 \mathrm{~m} / \mathrm{s}$ (vector), and wind $>12.5 \mathrm{~m} / \mathrm{s}$ (bold vector).

The BRT results predicted on 30 August 2015 are shown in Figure 8. For the spatial and numerical comparison of the three predictions, a consistent legend with the temperature varying from $23{ }^{\circ} \mathrm{C}$ to $33^{\circ} \mathrm{C}$ was used. The figures on the left and right show spatial distributions and histograms of grid values inside the boundary of Seoul City, respectively. In the case of LDAPS_temp (Figure 8a), the 1.5-km grid spacing was interpolated to $25 \mathrm{~m}$. LM_BRT (Figure 8b) and SVM_BRT (Figure 8c) have spatial resolutions of $25 \mathrm{~m}$, and the urban surface is presented in more detail than the LDAPS_temp (Figure 8a). Regarding the spatial distribution of the LDAPS_temp, the characteristics tend to reflect land use, such as forests and urban environments. In LM_BRT, details of land-cover characteristics, such as building area, height variables, and road surface parameters on the ground surface were reflected along the trend of LDAPS_temp. In SVM_BRT, land-cover properties, such as topographic height, aspect, slope, impervious surface parameters, and natural cover variables, are also reflected. In the LDAPS_temp histogram, the temperature inside Seoul is distributed from $25.5^{\circ} \mathrm{C}$ to $32{ }^{\circ} \mathrm{C}$, with the highest frequencies appearing from $28.5^{\circ} \mathrm{C}$ to $31.5^{\circ} \mathrm{C}$. The maximum temperature in LDAPS_temp is shown to be $32{ }^{\circ} \mathrm{C}$, but it can be seen that the area is more than $32{ }^{\circ} \mathrm{C}$ in LM_BRT and SVM_BRT (right side of Figure $8 \mathrm{~b}, \mathrm{c}$ ). The standard deviation is the highest in the LM_BRT histogram, with a wider range of temperatures and relatively higher frequencies. Similar to LM_BRT, the temperature range in SVM_BRT is wider $\left(27.5-28^{\circ} \mathrm{C}\right)$, and the highest frequency appears in the Han River area. On 30 August 2015, when the SWS observatory recorded a temperature of $31^{\circ} \mathrm{C}$, the temperature inside Seoul showed a deviation of about $10^{\circ} \mathrm{C}$. In other words, regions with relatively high and low temperatures can be classified based on the forecasting model. In particular, the highest temperature reported by the SWS is $31^{\circ} \mathrm{C}$, but the histograms showed areas with temperatures greater than $31^{\circ} \mathrm{C}$. 

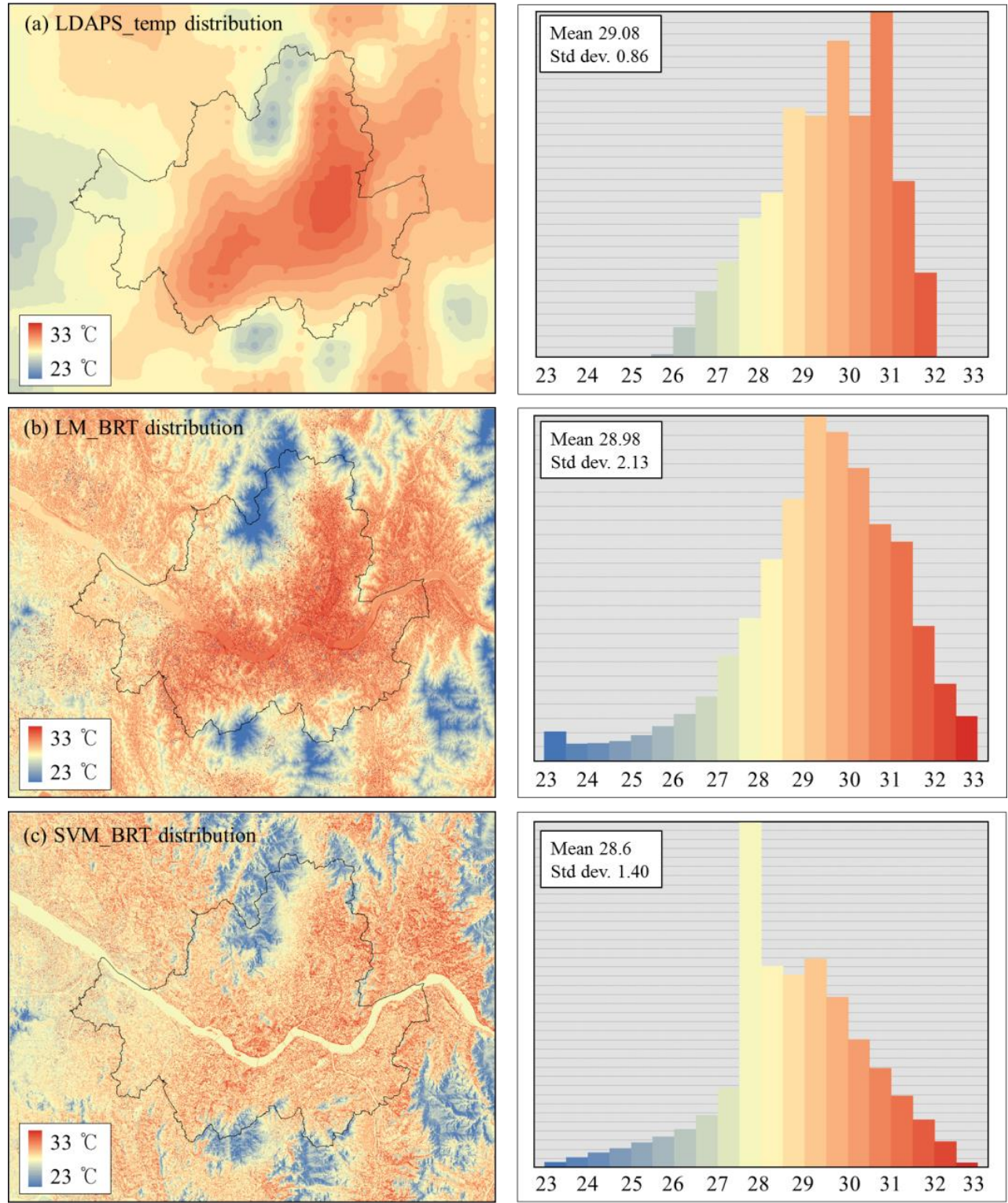

Figure 8. BRT distribution of daily maximum temperatures estimated for 30 August 2015. The left side of the figure shows the spatial distribution of temperatures, and the right side of the figure shows the zonal histogram for the areas within the boundary of Seoul City.

Figure 9 shows the results of the BRT estimation for the Songpa area $(4.5 \mathrm{~km} \times 4 \mathrm{~km})$ in Seoul City. The horizontal temperature deviation in LDAPS_temp (Figure 9a) is $2{ }^{\circ} \mathrm{C}$, and that in LM_BRT (Figure 9b) and in SVM_BRT (Figure 9c) is approximately $7^{\circ} \mathrm{C}$, because topography, building heights, and land use have effects on building-scale temperature. The topography, building heights, and land use, such as rivers, riverside, building structure, lakes, and vegetation, are not resolved in LDAPS_temp (see Figure 9a), but, in LM_BRT and SVM_BRT, they are shown in more spatial detail (see Figure 9b,c). In the case of LM_BRT, it can be confirmed that the daily maximum temperature is high at the riverside impervious area (bicycle road, parking lot, sports facilities) and the daily maximum temperature is relatively low in areas with high-rise apartment buildings (blue-colored grid). In the low-rise and high-density building areas (yellow), the characteristics of high-rise buildings can be distinguished. SVM_BRT shows a more gradual estimation of spatial daily maximum temperature variability than does LM_BRT. 

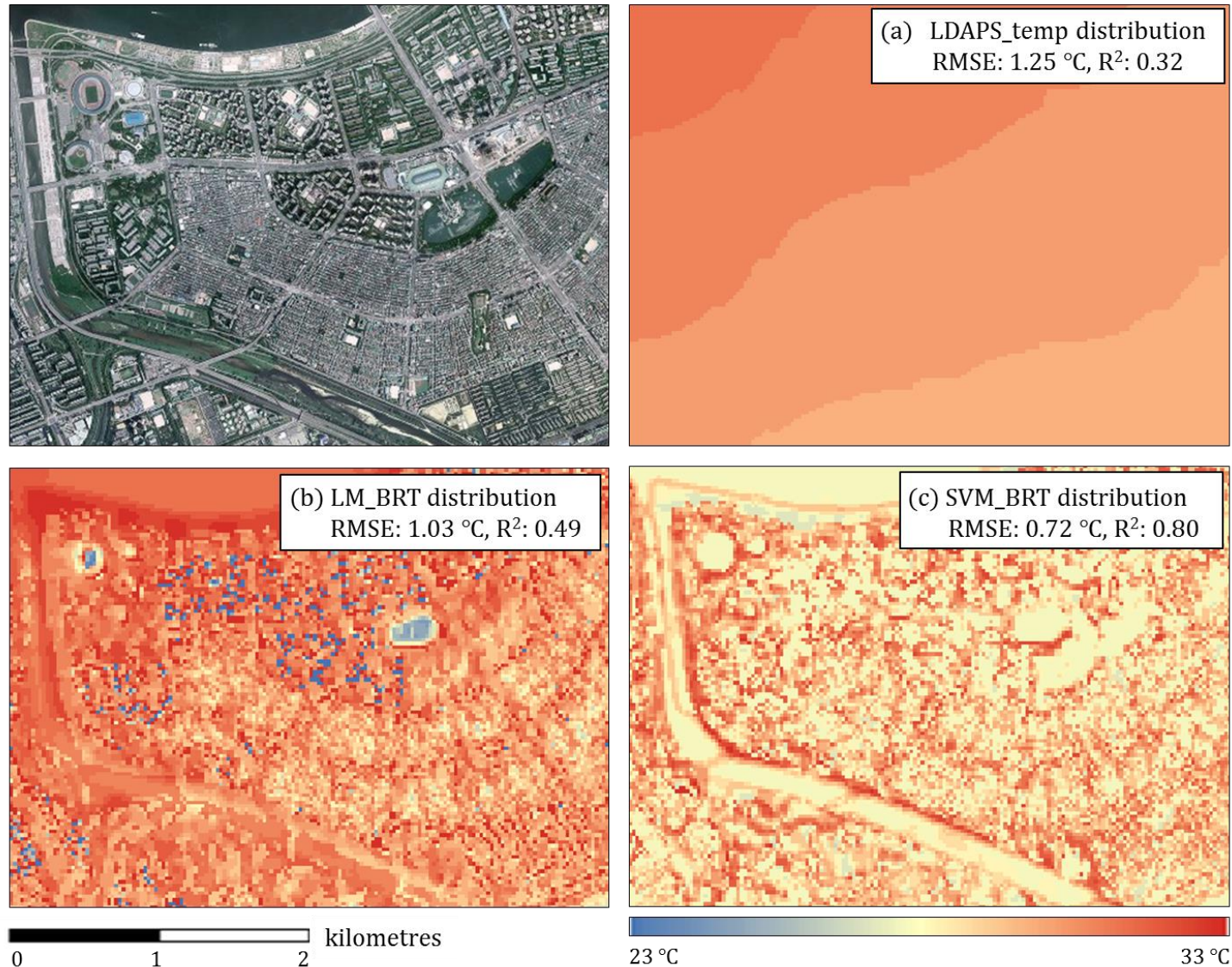

Figure 9. Aerial photography and BRT distribution of daily maximum temperatures estimated in the Songpa area of Seoul on 30 August 2015.

\subsection{BRT Evaluation Using Korea Meteorological Administration (KMA) Ground Observation Data}

\subsubsection{Evaluation of Time Series Results of Daily Maximum Temperatures}

In this study, temperatures from July to September 2015 for 61 days (July: 21 days, August: 18 days, September: 22 days) were estimated, except for on dates in which data were missing, using air temperature data from June to August 2015. The evaluation of the daily maximum temperatures of the LDAPS_temp, LM_BRT, and SVM_BRT at 52 points was performed. Figure 10 shows the averaged RMSE (root-mean-square error) of the daily maximum air temperatures at the 52 points, estimated during 61 days for LDAPS_temp, LM_BRT, and SVM_BRT. The results of the two statistical methods, which are closer to the observed values, showed lower values than does LDAPS_temp. The RMSE for almost all dates are considered to be better than those of the LDAPS_temp values.

The estimated temperature of LM_BRT or SVM_BRT is higher resolution, showing the local surface characteristics related to temperature. In particular, the RMSE of the estimated daily maximum air temperature was lowest in SVM_BRT. Nevertheless, it is necessary to conduct a detailed comparative analysis of the days on which the best $\left(0.5^{\circ} \mathrm{C}, 24\right.$ August $)$ and worst $\left(3.8^{\circ} \mathrm{C}, 25\right.$ August $)$ performances were observed.

In order to analyze the driving factors of the two cases, data from SWS were plotted (adding two days before and after) for 23-26 August. On 23 and 24 August, temperatures exceeded $30{ }^{\circ} \mathrm{C}$, but the highest temperature was $22.1^{\circ} \mathrm{C}$ on 25 August, because of precipitation from 09:00 to 20:00 LST (Figure 11). This BRT model shows that there are limitations in estimating the daily maximum temperature during precipitation events. In a follow-up study, it is necessary to consider precipitation events in the training data of the model for the production of BRT under all weather conditions. 


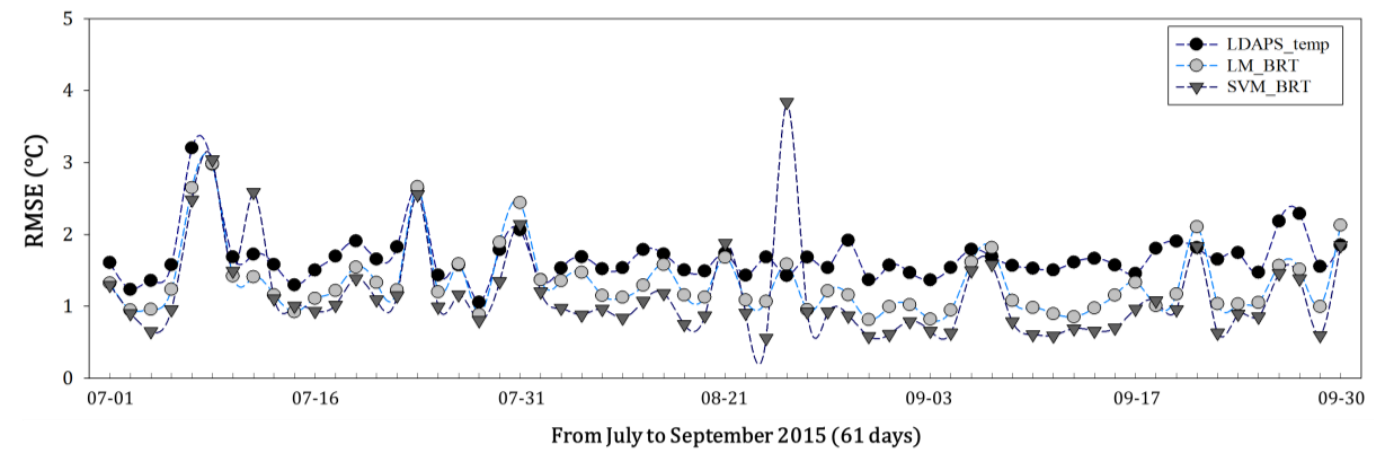

Figure 10. Time series of the root-mean-square error (RMSE) of the estimated Local Data Assimilation and Prediction System (LDAPS; black dots), LM_BRT (linear regression model; gray dots), and SVM_BRT (support vector machine; gray triangles) at 52 KMA AWS sites in Seoul during July to September 2015.

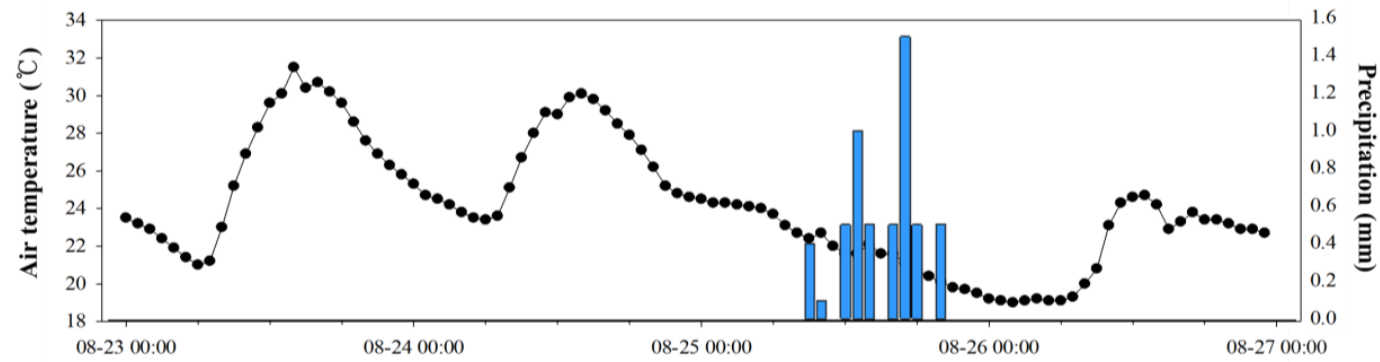

Figure 11. Time series of observed air temperature and precipitation at the Seoul weather station (SWS) during 23-26 August.

The estimated daily maximum temperature for 61 days was classified according to the following conditions: (1) days of the threshold temperature of Seoul (above $29.4{ }^{\circ} \mathrm{C}$ ) and (2) days of general summer (less than $29.4{ }^{\circ} \mathrm{C}$ ). RMSE and $\mathrm{R}^{2}$ were calculated for the two conditions, and the results are shown in Table 4. Regarding the RMSE results, LDAPS and LM were similar under both conditions, whereas SVM was the best in the threshold temperature condition. The overall mean RMSE was also analyzed to be the lowest in SVM. Regarding $\mathrm{R}^{2}$ results, SVM showed the highest value for the entire period, especially under the threshold temperature condition.

Table 4. Evaluation results (mean RMSE and $\mathrm{R}^{2}$ ) according to observed air temperature at 52 KMA AWSs.

\begin{tabular}{cccccccc}
\hline Condition & Days & \multicolumn{3}{c}{ RMSE } & \multicolumn{3}{c}{$\mathbf{R}^{2}$} \\
\cline { 2 - 8 } & LDAPS & LM & SVM & LDAPS & LM & SVM \\
\hline $\begin{array}{c}\text { Threshold temperature of } \\
\begin{array}{c}\text { Seoul (above } 29.4^{\circ} \mathrm{C} \text { ) } \\
\text { General summer } \\
\left(\text { less than } 29.4^{\circ} \mathrm{C}\right)\end{array}\end{array}$ & 28 & 1.713 & 1.309 & 1.076 & 0.012 & 0.573 & 0.787 \\
\hline Total & 61 & 1.659 & 1.348 & 1.249 & 0.005 & 0.590 & 0.752 \\
\hline
\end{tabular}

\subsubsection{Evaluation of the Spatial Distribution of Daily Maximum Temperature}

In order to verify the estimated air temperature, the observed daily maximum temperatures at 52 AWS sites were used. For verification, the target days were no-precipitation days in the summer of 2015 at SWS with cloud amounts less than 20\%. Eleven target days were selected. In Figure 12, 
the results verification of four arbitrary example days at 15:00 LST (4 July, 27 August, 17 September, 26 September) are shown. In all four cases, the mean RMSE of all sites of the estimated air temperature of SVM_BRT was the smallest, and $R^{2}$ was the largest, indicating a high correlation. However, the RMSE of SVM_BRT increased in September compared to in July. As shown in Figure 12c,d, in September, the estimated air temperature (gray) was found to be higher than the observed air temperature (red). This can be attributed to the use of data from June, July, and August to train the BRT model. Therefore, seasonal characteristics are not reflected in the estimated values for September.
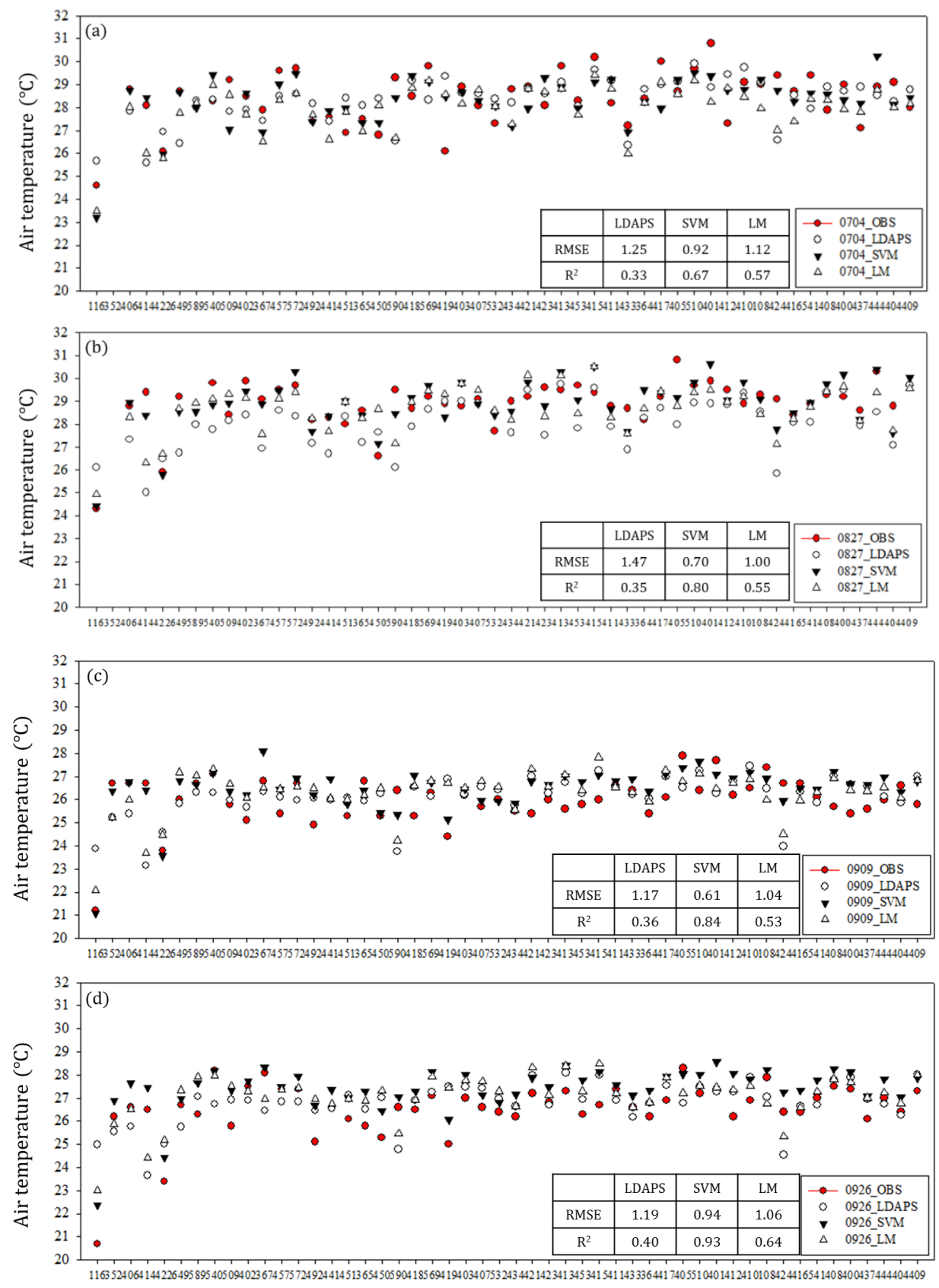

Figure 12. Comparison of the distribution of estimated (gray) and observed (red) air temperatures at 15:00 LST during clear days. The four case days are (a) 4 July; (b) 27 August; (c) 9 September; and (d) 26 September. The $x$-axis represents sequentially sorted AWSs, according to impervious area ratios.

However, the $\mathrm{R}^{2}$ value increased in September. The reason for the increased correlation at all sites can be considered to be the reasonable reflection of the surface characteristics of each site in the 
observed air temperature. Summers in Seoul are dominated by oceanic anticyclones, and the dynamic elements are weak. On the other hand, dynamic wind elements become active again in autumn due to the influence of migratory cyclones, and the change in the atmosphere becomes more apparent due to the decrease in humidity.

As a result, the larger diurnal variations in September result in higher correlations.

\subsubsection{BRT Evaluation Using SKT Observation Data}

LDAPS_temp, SVM_BRT, and LM_BRT results were evaluated using SKT meteorological data not used as training data in the BRT model. For the selected 11 days (clear days with less than $20 \%$ cloudiness; Section 4.2.2), the daily maximum air temperature was verified at 255 sites. The RMSE of the 11 days was analyzed (LDAPS_temp $1.14{ }^{\circ} \mathrm{C}$, SVM_BRT $1.23^{\circ} \mathrm{C}$, and LM_BRT $3.66^{\circ} \mathrm{C}$ ), and the $\mathrm{R}^{2}$ of the 11 days was also analyzed (LDAPS_temp 0.43, SVM_BRT 0.40, and LM_BRT 0.13). With respect to the RMSE and $\mathrm{R}^{2}$, there are no clear differences between the LDAPS_temp and SVM_BRT, while LM_BRT shows poor values for both statistical measures. The correlation was higher with the use of KMA observational data. All SKT observation equipment are installed on the roofs of buildings, and a deviation from pedestrian height based on the observation altitude may exist. Furthermore, because SKT observation data were obtained only for impervious surfaces of the city, various characteristics of other surface types may not be reflected.

In order to conduct the evaluations for all weather conditions, 61 case study days were used to verify the SVM_BRT results with higher correlations than LM_BRT at all 255 sites. The RMSE was low and the $\mathrm{R}^{2}$ was high at $29.4{ }^{\circ} \mathrm{C}$ or higher (Table 5). Figure 13 shows the spatial distribution of the results. Because of the diverse characteristics of the sites, the RMSE and $\mathrm{R}^{2}$ also varied in different areas, usually with high RMSEs in high-rise building areas. For an area with high RMSE and low $\mathrm{R}^{2}$, an additional parameter should be considered (e.g., other surface parameters).

Table 5. Evaluation results according to SKT observation air temperature data.

\begin{tabular}{cccccccc}
\hline \multirow{2}{*}{ Condition } & Days & \multicolumn{3}{c}{ RMSE (SVM_BRT) } & \multicolumn{3}{c}{$\mathbf{R}^{\mathbf{2}}$ (SVM_BRT) } \\
\cline { 3 - 8 } & Mean & Min & Max & Mean & Min & Max \\
\hline $\begin{array}{c}\text { Threshold temperature of } \\
\begin{array}{c}\left.\text { Seoul (above } 29.4^{\circ} \mathrm{C}\right) \\
\text { General summer } \\
\left(\text { less than } 29.4^{\circ} \mathrm{C}\right)\end{array}\end{array}$ & 28 & 1.752 & 0.881 & 4.303 & 0.434 & 0.060 & 0.752 \\
\hline Total & 33 & 2.327 & 0.918 & 4.095 & 0.383 & 0 & 1.000 \\
\hline
\end{tabular}
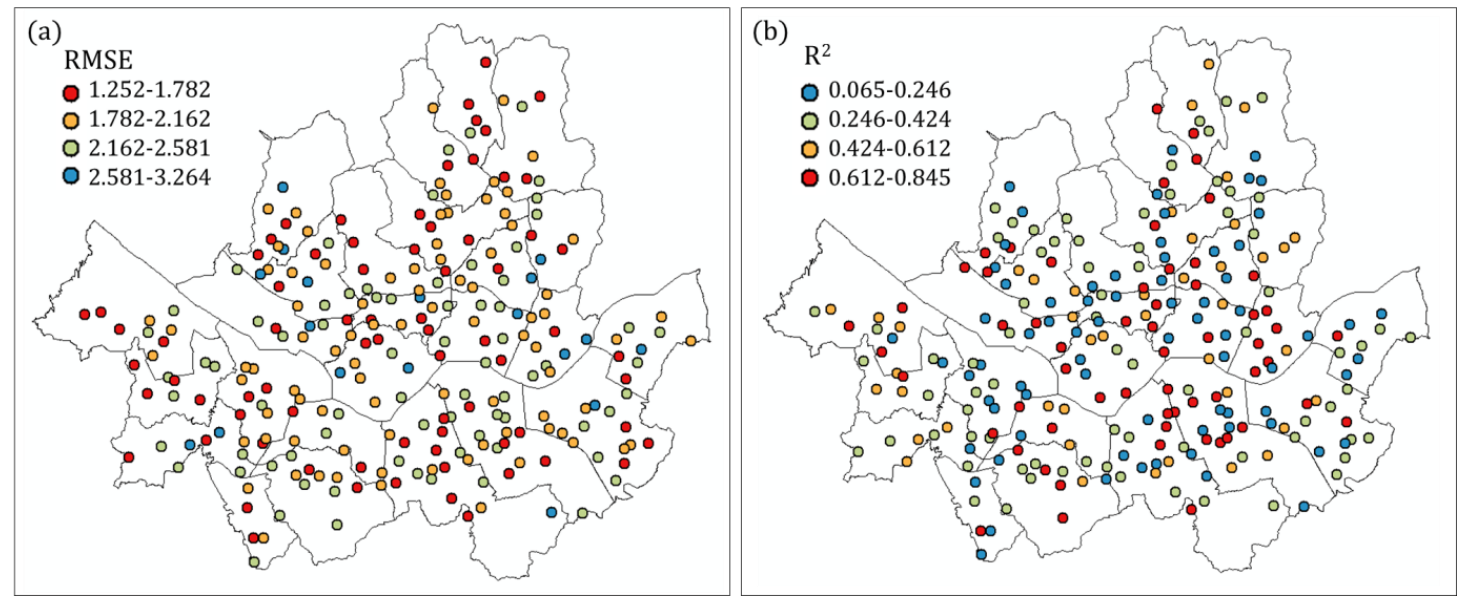

Figure 13. Spatial distribution of evaluation results according to $\mathrm{DT}_{\max }$ data for all days. The evaluation indices using high-density observational data are RMSE (a) and $\mathrm{R}^{2}(\mathbf{b})$. 


\subsection{Heat Exposure Map for Local Weather Services}

In order to produce information about heat exposure for local weather services for the Seoul citizen, grid information corresponding to the population distribution was adapted to SVM_BRT. In other words, grids corresponding to urbanized areas inhabited by people, excluding mountains and rivers (Figure 14a), were extracted, and zonal statistics by the area of the self-government district unit were calculated (Figure 14b). The spatially averaged temperature information reconstructed in the area's self-government district units was used to generate a potential heat exposure map, reflecting the local characteristics of the area. This summer heat exposure map can be used in connection with the climatic environment of the city of Seoul for related local governments policies, residents' autonomous center activities, and volunteer activities. The city of Seoul consists of 25 districts and 433 administrative districts. There are 423 civic self-governing centers in the city and about 3 million volunteers. Moreover, the self-governing activities of citizens are increasing. Heat exposure information will be provided to district, city, and autonomous center units, which will guide activities that mitigate negative impacts and maintain positive impacts.

Eventually, heat exposure-sensitive group such as alienated old people are target beneficiaries of the proposed local weather service. The shared prediction of thermal risk in Seoul with a survey of social alienation such as location would be a starting point for the volunteer's help service [48]. It can be an efficient collaboration case or a citizen's self-governance framework in Seoul between proposed local weather service and community level reaction (Figure 14c).
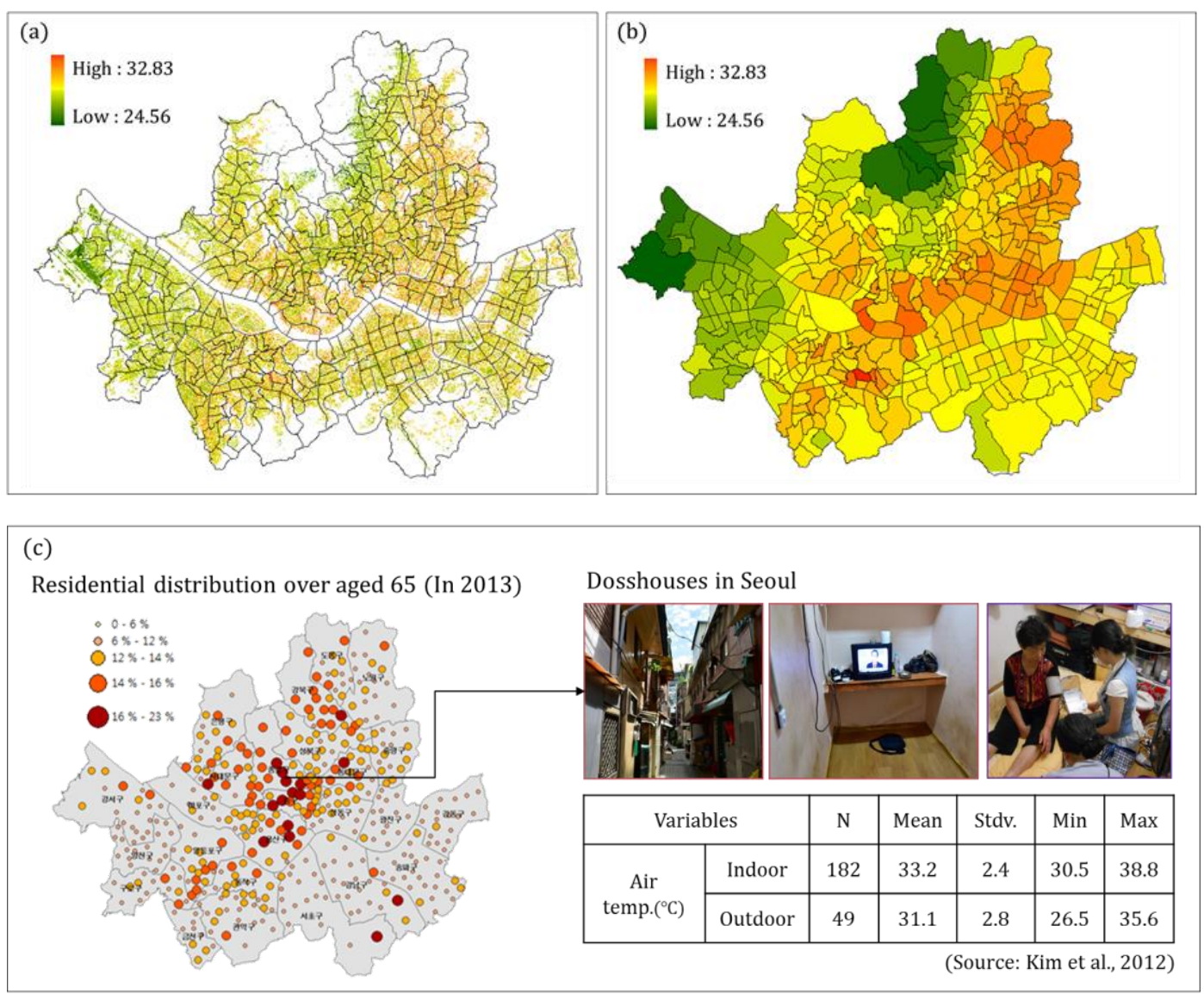

Figure 14. Proposed collaboration framework between local weather service (grid (a) and self-government district (b)) and following self-governance (c). 


\section{Conclusions}

In this study, the BRT model was developed to improve the detail and accuracy of air temperature data from LDAPS, which is an operational model of the Korea Meteorological Administration. Urban air temperatures near the surface with building-scale resolution from the numerical model have lower performance compared to the observational data, since urban surface characteristics are not accounted for in the numerical model. In order to apply urban surface characteristics to near-surface air temperatures and to incorporate observational information with irregular points to building-scale resolution spatial air temperatures, the BRT model was developed. The BRT model estimates air temperature at the height of a pedestrian. Surface parameters reflecting the urban environment at the building-scale and street-level are calculated and entered into the model. A temperature distribution of $25 \mathrm{~m}$ resolution was determined for the Seoul area, and spatial information was processed using SVM and LM methods. The SVM method, in which selective variables were applied, showed higher accuracy than did the LM method, in which fixed variables were applied. Nevertheless, the accuracy was lower on days with precipitation, because precipitation days were excluded from the training process in SVM_BRT. On the other hand, if the $25 \mathrm{~m}$ resolution temperature information is necessary, the seasonal variability should be considered to improve the accuracy of the predicted temperatures. This implies that seasonal variability should be considered, and background data are needed. In order to estimate air temperature accurately, various weather variables (e.g., cloud quantity, wind speed, solar radiation, radiation flux, precipitation) and time series weights (monthly characteristics, temporal characteristics) should be incorporated. Regarding SKT meteorological data, which were not used as training data for the BRT model, almost all observation sites are located on impervious surfaces, and the accuracy of the estimation is limited because of differences in the altitudes of high-rise buildings. For this reason, the prediction accuracy of daily maximum temperature was lower than that using KMA weather data. However, relatively high accuracy was generally achieved at high temperatures (29.4 ${ }^{\circ} \mathrm{C}$ or higher).

With the dense population, the spatial distribution of heat-sensitive individuals in Seoul, such as the elderly, infants, and residents of villages over 30 years old or with construction that is sensitive to heat exposure, should also be considered. For management of vulnerable groups in the summer, priorities can be selected on a detailed regional basis (e.g., by the self-government district unit). For example, detailed information on potential local air temperature can be obtained using the BRT model even during non-heat-wave periods. Such information will enable direct management regarding the corresponding heat exposure-sensitive group. In the long term, thermal reduction activities are required for areas with thermal stress, in order to improve urban sustainability and resilience. To this end, the Seoul Metropolitan Government is undertaking measures such as increasing urban forests, roadside tree planting, rooftop greening, wall greening, and cool roofing, which can be further implemented in areas with high temperatures.

Air temperature information provided as heat exposure information for pedestrians can be used to manage the response to heat-waves and tropical nights in administrative districts of urban areas. The BRT model developed in this study can be used to mitigate the heat stress of citizens due to heat exposure. Improvements in the short-term response to urban heat-waves and the long-term response to urban heat islands can be achieved through this numerically modeled local weather information.

Author Contributions: C.Y. conceived and designed the experiments; C.Y. and Y.S. performed the experiments; C.Y. and J.W. analyzed the data; Y.S. contributed to data collection and analysis tools; C.Y. wrote the paper; Anonymous reviewers and editors gave scientific comments.

Acknowledgments: This work was funded by the Korea Meteorological Administration Research and Development Program under Grant KMI (KMI2018-01410).

Conflicts of Interest: The authors declare no conflict of interest. The founding sponsors had no role in the design of the study; in the collection, analyses, or interpretation of data; in the writing of the manuscript, and in the decision to publish the results. 


\section{References}

1. Fink, A.H.; Brucher, T.; Kruger, A.; Leckebusch, G.C.; Pinto, J.G.; Ulbrich, U. The 2003 European summer heatwaves and drought-Synoptic diagnosis and impacts. Weather 2004, 59, 209-215. [CrossRef]

2. Ebi, K.L.; Teisberg, T.J.; Kalkstein, L.S.; Robinson, L.; Weiher, R.F. Heat watch/warning systems save lives: Estimated costs and benefits for Philadelphia 1995-1998. Bull. Am. Meteorol. Soc. 2004, 85, 1067-1073. [CrossRef]

3. Kalkstein, L.S.; Greene, J.S.; Mills, D.; Perrin, A.; Samenow, J.; Cohen, J.-C. Analog European heat waves for U.S. cities to analyze impacts on heat-related mortality. Bull. Am. Meteorol. Soc. 2008, 89, 75-86. [CrossRef]

4. Greene, J.S.; Kalkstein, L.S.; Kim, K.R.; Choi, Y.J.; Lee, D.G. The application of the European heat wave of 2003 to Korean cities to analyze impacts on heat-related mortality. Int. J. Biometeorol. 2016, 60, $231-243$. [CrossRef] [PubMed]

5. Masato, G.; Bone, A.; Charlton-Perez, A.; Cavany, S.; Neal, R.; Dankers, R. Improving the Health Forecasting Alert System for Cold Weather and Heat-Waves In England: A Proof-of-Concept Using Temperature-Mortality Relationships. PLoS ONE 2015, 10, e0137804. [CrossRef] [PubMed]

6. Chen, B.; Tang, X. Translating weather forecast into impact-relevant information: Practice of impact-based forecast in weather forecast operation. In Proceedings of the World Weather Open Science Conference, Montréal, QC, Canada, 16-21 August 2014. Available online: https://www.rmets.org/events/worldweather-open-science-conference-2014 (accessed on 28 November 2017).

7. Bouchet, V.; Jalkanen, L.; Carmichael, G. Megacities and large urban complexes: Next phase of the GURME project. In Proceedings of the WWOSC 2014 Annual Meeting, Montréal, QC, Canada, 16-21 August 2014.

8. Lee, C. Urban meteorological networks: An urban climatologists panacea? In Proceedings of the International Conference on Urban Climate, Toulouse, France, 20-24 July 2015. Available online: http:/ / www.meteo.fr/ icuc9 (accessed on 28 November 2017).

9. Baklanov, A. From urban meteorology, climate and environment research to urban integrated services. In Proceedings of the ICUC Annual Meeting, Toulouse, France, 20-24 July 2015.

10. Leroyer, S.; Belair, S.; Abrahamowicz, M.; Spacek, L.; Filion, A.-B. Numerical weather prediction system dedicated to urban comfort and safety during the 2015 Pan-American games in Toronto. In Proceedings of the ICUC Annual Meeting, Toulouse, France, 20-24 July 2015.

11. Grimmond, C.S.B.; Tan, J.; Fu, X.; Ward, H. Urban Climate Services in China: Current capabilities and future needs. In Proceedings of the ICUC Annual Meeting, Toulouse, France, 20-24 July 2015.

12. Yi, C.; Kwon, H.G.; Kim, K.R.; An, S.M.; Choi, Y.J.; Scherer, D. Climate information application for improved planning and management of cities. In Proceedings of the ICUC Annual Meeting, Toulouse, France, 20-24 July 2015.

13. Ronda, R.; Steeneveld, G.-J.; Attema, J.; Heusinkveld, B.; Holtslag, B. Summer in the city: Towards high resolution forecasting of urban weather. In Proceedings of the ICUC Annual Meeting, Toulouse, France, 20-24 July 2015.

14. IPCC. Summary for Policymakers. Climate Change 2014: Impacts, Adaptation, and Vulnerability; Part A: Global and Sectoral Aspects; Contribution of Working Group II to the Fifth Assessment Report of the Intergovernmental Panel on Climate Change; Cambridge University Press: Cambridge, UK; New York, NY, USA, 2014; pp. 1-32.

15. Tsangari, H.; Paschalidou, A.; Vardoulakis, S.; Heaviside, C.; Konsoula, Z.; Christou, S.; Georgiou, K.; Ioannou, K.E.; Mesimeris, T.; Kleanthous, S.; et al. Human mortality in Cyprus: The role of temperature and particulate air pollution. Reg. Environ. Chang. 2016, 16, 1905-1913. [CrossRef]

16. Akbari, H.; Taha, H. The impact of trees and white surfaces on residential heating and cooling energy use in four Canadian cities. Energy 1992, 17, 141-149. [CrossRef]

17. Institute Meteorological Science of Korea. Report on Advanced Research on Meteorological Sciences: Advanced Research on Industrial Meteorology; National Institute Meteorological Science of Korea: Seoul, Korea, 2009.

18. Tran, H.; Uchihama, D.; Ochi, S.; Yasuoka, Y. Assessment with satellite data of the urban heat island effects in Asian mega cities. Int. J. Appl. Earth Obs. Geoinf. 2006, 8, 34-48. [CrossRef]

19. Narumi, D.; Kondo, A.; Shimoda, Y. Effects of anthropogenic heat release upon the urban climate in a Japanese megacity. Environ. Res. 2009, 109, 421-431. [CrossRef] [PubMed]

20. Kyselý, J.; Kim, J. Mortality during heat waves in South Korea, 1991 to 2005: How exceptional was the 1994 heat wave. Clim. Res. 2009, 38, 105-116. [CrossRef] 
21. Korea Meteorological Administration. Report on 2016 Abnormal Climate Report; Korea Meteorological Administration: Seoul, Korea, 2016.

22. Davis, R.E.; Knappenberger, P.C.; Novicoff, W.M.; Michaels, P.J. Decadal changes in summer mortality in US cities. Int. J. Biometeorol. 2003, 47, 166-175. [PubMed]

23. Hajat, S.; Vardoulakis, S.; Heaviside, C.; Eggen, B. Climate change effects on human health: Projections of temperature-related mortality for the UK during the 2020s, 2050s and 2080s. J. Epidemiol. Community Health 2014, 68, 641-648. [CrossRef] [PubMed]

24. Kim, J.; Lee, D.; Kysely, J. A synoptic and climatological comparison of record-breaking heat waves in Korea and Europe. Atmosphere Korea 2008, 18, 355-365.

25. Kim, J.; Lee, D.; Kysely, J. Characteristics of heat acclimatization for major Korean cities. Atmosphere Korea 2009, 19, 309-318.

26. Kim, J.; Lee, D.; Park, I.S.; Choi, B.C.; Kim, J.S. Influences of heat waves on daily mortality in South Korea. Atmosphere Korea 2006, 16, 269-278.

27. Lee, D.; Choi, Y.J.; Kim, K.R.; Byon, J.Y.; Kalkstein, L.S.; Scott, C.S. Development of heat-health warning system based on regional properties between climate and human Health. Clim. Chang. Res. 2010, 1, 109-120.

28. Lee, D.; Byon, J.Y.; Choi, Y.J.; Kim, K.R.; Kalkstein, L.S. An operational heat-health warning system for Seoul: During the summer of 2008. In Proceedings of the Korea Meteorology Society, Seoul, Korea, 23-24 April 2009.

29. Yi, C.; Kim, K.R.; An, S.M.; Choi, Y.J.; Holtmann, A.; Jänicke, B.; Fehrenbach, U.; Scherer, D. Estimating spatial patterns of air temperature at building-resolving spatial resolution in Seoul, Korea. Int. J. Climatol. 2016, 36, 533-549. [CrossRef]

30. Jänicke, B.; Meier, F.; Lindberg, F.; Schubert, S.; Scherer, D. Towards a city-wide analysis of mean radiant temperature at high spatial resolution An example from Berlin, Germany. Urban Clim. 2016, 15, 8398. [CrossRef]

31. Kim, K.R.; Yi, C.; Lee, J.S.; Meier, F.; Jänicke, B.; Fehrenbach, U.; Scherer, D. BioCAS: Biometeorological Climate impact Assessment System for building-scale impact assessment of heat-stress related mortality. DIE ERDE J. Geogr. Soc. Berlin 2014, 145, 62-79.

32. Yi, C.; An, S.M.; Kim, K.R.; Kwon, H.G.; Min, J.S. Surface Micro-Climate Analysis Based on Urban Morphological Characteristics: Temperature Deviation Estimation and Evaluation. Atmosphere Korea 2016, 26, 445-459. [CrossRef]

33. Harlan, S.L.; Brazel, A.J.; Prashad, L.; Stefanov, W.L.; Larsen, L. Neighborhood microclimates and vulnerability to heat stress. Soc. Sci. Med. 2006, 63, 2847-2863. [CrossRef] [PubMed]

34. Shahmohamadi, P.; Che-Ani, A.I.; Etessam, I.; Maulud, K.N.A.; Tawil, N.M. Healthy environment: The need to mitigate urban heat island effects on human health. Procedia Eng. 2011, 20, 61-70. [CrossRef]

35. Korea Meteorological Administration. Report on Seoul Incheon Gyeonggi-Do Climate Change Forecast; Korea Meteorological Administration: Seoul, Korea, 2012.

36. Stewart, I.D.; Oke, T.R. Local climate zones for urban temperature studies. Bull. Am. Meteorol. Soc. 2012, 93, 1879-1900. [CrossRef]

37. Korea Meteorological Administration. Numerical Data Application Manual; KMA: Seoul, Korea, 2011; pp. $13-17$. ISBN 11-1360395-000252-01.

38. Korea Meteorological Administration. Quality Control Manual for National Climate Data; KMA: Seoul, Korea, 2011; p. 44.

39. Oh, G.L.; Lee, S.J.; Choi, B.C.; Kim, J.; Kim, K.R.; Choi, S.W.; Lee, B.L. Quality control of agro-meteorological data measured at Suwon Weather Station of Korea Meteorological Administration. Korean J. Agric. For. Meteorol. 2015, 17, 25-34. [CrossRef]

40. Grimmond, C.S.B.; Roth, M.; Oke, T.R.; Au, Y.C.; Best, M.; Betts, R.; Carmichael, G.; Cleugh, H.; Dabberdt, W.; Emmanuel, R.; et al. Climate and more sustainable cities: Climate information for improved planning and management of cities (producers/capabilities perspective). Procedia Environ. Sci. 2010, 1, 247-274. [CrossRef]

41. Bechtel, B.; Wiesner, S.; Zakšek, K. Estimation of dense time series of urban air temperatures from multitemporal geostationary satellite data. IEEE J. Sel. Top. Appl. Earth Obs. Remote Sens. 2014. [CrossRef]

42. Hoffmann, P.; Krueger, O.; Schlünzen, K.H. A statistical model for the urban heat island and its application to a climate change scenario. Int. J. Climatol. 2012, 32, 1238-1248. [CrossRef]

43. Arnds, D.; Böhner, J.; Bechtel, B. Spatio-temporal variance and meteorological drivers of the urban heat island in a European city. Theor. Appl. Climatol. 2015, 1-19. [CrossRef] 
44. Lantz, B. Machine Learning with R; Packt Publishing Ltd.: Birmingham, UK, 2013.

45. CRAN Task View: Machine Learning \& Statistical Learning. Available online: https://cran.r-project.org/ web/views/MachineLearning.html (accessed on 30 January 2018).

46. Wu, X.; Kumar, V.; Quinlan, J.R.; Ghosh, J.; Yang, Q.; Motoda, H.; McLachlan, G.J.; Ng, A.; Liu, B.; Philip, S.Y.; et al. Top 10 algorithms in data mining. Knowl. Inf. Syst. 2008, 14, 1-37. [CrossRef]

47. Yi, C.; Kim, K.R.; Choi, Y.J.; Won, H.Y.; Scherer, D. Nocturnal Surface Cooling and Cold Air Transport Analysis Based on High Density Observation-A Case Study of Eunpyeong New Town in Seoul. J. Korean Assoc. Geogr. Inf. Stud. 2012, 15, 124-137. [CrossRef]

48. Kim, Y.M.; Kim, S.; Cheong, H.K.; Ahn, B.; Choi, K. Effects of heat wave on body temperature and blood pressure in the poor and elderly. In Proceedings of the Korean Society of Environmental Health and Toxicology, Seoul, Korea, 10 May 2012.

(C) 2018 by the authors. Licensee MDPI, Basel, Switzerland. This article is an open access article distributed under the terms and conditions of the Creative Commons Attribution (CC BY) license (http://creativecommons.org/licenses/by/4.0/). 